\title{
Tinjauan Aspek Keamanan dan Kerahasiaan Rekam Medis di Rumah Sakit Setia Mitra Jakarta Selatan
}

\author{
Review of Safety and Lifestyle Aspects of Medical Records at Rumah Sakit \\ Setia Mitra Jakarta Selatan
}

\author{
Siswati1) \\ Dea Ayu Dindasari2) \\ 1,2)Akademi Perekam Medis dan Informasi Kesehatan Bhumi Husada Jakarta \\ Jl. Raharja No. 15 Pondok Pinang, Kebayoran Lama, Jakarta Selatan \\ E-mail :dindasarideaayu@gmail.com
}

\begin{abstract}
Maintaining the confidentiality of the patient's medical record, required storage of medical records that meet the requirements in maintaining security and confidentiality. Medical record storage can be said to be good if the room guarantees security and avoid the threat of loss, neglect, disaster and anything that can jeopardize the medical record. The medical record storage room at Setia Mitra Hospital is not yet secure, because the door is unlocked. Besides nurses, radiology and nutrition can enter the medical record storage room and some medical records were found damaged. The general purpose of this study was to determine the security and confidentiality aspects in the medical record storage room. This research method is qualitative with a case study approach to illustrate how the security and confidentiality aspects in the Setia Mitra Hospital medical record storage room. Data collection techniques by observation and interview. The results found that the security and confidentiality policies have been made but have not been implemented well. The conclusion from the results of this study was only found about security policies while standard operating procedures related to the security and confidentiality of medical records have not been made. The physical medical record does not guarantee the safety and confidentiality of the contents of the medical record. Medical record storage room does not guarantee the security of medical record storage. The Setia Mitra Hospital leadership should be able to reaffirm the established policies related to the security and confidentiality of medical records, in addition to that the SPO was made related to the security and confidentiality of medical records.
\end{abstract}

Keywords : Security and confidentiality; storage room; medical records

\begin{abstract}
Abstrak
Menjaga kerahasiaan rekam medis pasien, diperlukan ruang penyimpanan rekam medis yang memenuhi ketentuan dalam menjaga keamanan dan kerahasiaan. Ruang penyimpanan rekam medis dapat dikatakan baik apabila ruangan tersebut menjamin keamanan dan terhindar dari ancaman kehilangan, kelalaian, bencana dan segala sesuatu yang dapat membahayakan rekam medis. Ruang Penyimpanan rekam medis di Rumah Sakit Setia Mitra belum terjaga keamananya, karena ruang pintu tidak terkunci. Selain itu perawat, radiologi dan gizi dapat masuk kedalam ruang penyimpanan rekam medis dan beberapa rekam medis ditemukan rusak. Tujuan umum penelitian ini untuk mengetahui aspek keamanan dan kerahasiaan di ruang penyimpanan rekam medis. Metode penelitian ini adalah kualitatif dengan pendekatan studi kasus untuk menggambarkan bagaimana aspek keamanan dan kerahasiaan di ruang penyimpanan rekam medis RS Setia Mitra. Teknik pengumpulan data dengan cara observasi dan wawancara. Hasil penelitian ditemukan bahwa Kebijakan keamanan dan kerahasiaan sudah dibuat tetapi belum terlaksana dengan baik. Kesimpulan dari hasil penelitian ini hanya
\end{abstract}


ditemukan kebijakan tentang keamanan sedangkan standar prosedur operasioanal terkait keamanan dan kerahasiaan rekam medis belum dibuat. Fisik rekam medis belum menjamin keamanan dan kerahasiaan isi rekam medis. Ruang penyimpanan rekam medis belum menjamin keamanan penyimpanan rekam medis. Sebaiknya pimpinan RS Setia Mitra dapat menegaskan kembali adanya kebijakan yang ditetapkan terkait keamanan dan kerahasiaan rekam medis, selain itu dibuat SPO terkait keamanan dan kerahasiaan rekam medis.

Kata Kunci : Keamanan dan Kerahasiaan; Ruang Penyimpanan; Rekam Medis.

\section{Pendahuluan}

Rumah sakit adalah institusi pelayanan kesehatan bagi masyarakat dengan karakteristik khusus yang dipengaruhi oleh perkembangan ilmu pengetahuan kesehatan, kemajuan teknologi, dan kehidupan sosial ekonomi masyarakat. RS harus tetap mampu meningkatkan pelayanan yang lebih bermutu dan terjangkau oleh masyarakat agar terwujud derajat kesehatan yang setinggi-tingginya. Setiap rumah sakit wajib menyelenggarakan rekam medis untuk mendukung pelayanan kesehatan.

Rekam medis adalah berkas yang berisi catatan dan dokumen tentang identitas pasien, pemeriksaan, pengobatan, tindakan medis lain pada sarana pelayanan kesehatan untuk rawat jalan, rawat inap baik yang dikelola pemerintah maupun swasta. Isi Rekam medis bersifat rahasia yang harus dijaga oleh petugas kesehatan dan petugas rekam medis. Oleh karena itu rumah sakit berkewajiban menjaga keamanan dan kerhasiaan isi rekam medis pasien.

Peranan petugas rekam medis, dokter dan perawat dalam menjaga kerahasiaan rekam medis sesuai dengan standar prosedur operasional yang ditetapkan. Berdasarkan Undang-Undang RI No.29 tahun 2004 tentang Praktik Kedokteran Pasal 47 ayat 2 rekam medis harus disimpan dan dijaga kerahasiaanya oleh dokter dan dokter gigi dan pimpinan sarana pelayanan kesehatan.

Untuk menjaga kerahasiaan rekam medis pasien, diperlukan ruang penyimpanan rekam medis yang memenuhi ketentuan dalam menjaga keamanan dan kerahasiaan. Ruang rekam medis dapat dikatakan baik apabila ruangan tersebut menjamin keamanan dan terhindar dari ancaman kehilangan, kelalaian, bencana dan segala sesuatu yang dapat membahayakan rekam medis tersebut.

Berdasarkan observasi di RS Setia Mitra pada tanggal 13-15 Maret 2019 di ruang penyimpanan rekam medis, ditemukan beberapa masalah yang berkaitan dengan keamanan dan kerahasiaan rekam medis. Ada 2 (DUA) Ruang penyimpanan rekam medis yang terpisah, keadaan ini dapat mengakibatkan sulitnya pengawasan. Ruang penyimpanan rekam medis tidak dikunci sehingga petugas dari bagian lain dapat masuk ke ruang penyimpanan rekam medis. Selain itu ditemukan rekam medis yang rusak seperti robek dan terlipat. Hal ini disebabkan rak penyimpanan rekam medis sudah sangat padat.

\section{Rumusan Masalah}

Berdasarkan permasalahan tersebut, penulis ingin membahas "Tinjauan Aspek Keamanan Dan Kerahasiaan Rekam Medis di Rumah Sakit Setia Mitra Jakarta."

\section{Tujuan Penelitian}

1. Tujuan umum: untuk mengetahui gambaran keamanan dan kerahasiaan rekam medis di Rumah Sakit Setia Mitra Jakarta Selatan.

2. Tujuan Khusus :

a. Mengidentifikasi kebijakan tentang keamanan dan kerahasiaan ruang penyimpanan rekam medis.

b. Mengidentifikasi gambaran pelaksanaan dan kerahasiaan ruang penyimpanan rekam medis 
Pengertian Rekam Medis

Menurut Peraturan Menteri Kesehatan Republik Indonesia No. 55 tahun 2013 tentang Penyelenggaraan Pekerjaan Perekam Medis. Rekam Medis adalah berkas yang berisi catatan dan dokumen tentang identitas pasien, pemeriksaan, pengobatan, tindakan dan pelayanan.

Menurut Edna K. Huffman, Rekam Medis adalah fakta yang berkaitan dengan keadaan pasien, riwayat penyakit dan pengobatan masa lalu serta saat ini yang ditulis oleh profesi kesehatan yang memberikan pelayanan kepada pasien tersebut.

\section{Tujuan Rekam Medis}

Di dalam petunjuk teknis penyelenggaraan rekam medis departemen kesehatan RI tahun 2006 menyatakan bahwa:

Tujuan rekam medis adalah untuk menunjang tercapainya tertib administrasi dalam rangka upaya peningkatan pelayanan kesehatan di rumah sakit. Tanpa didukung suatu sistem pengelolaan rekam medis yang baik dan benar, tidak akan tercapai tertib administrasi rumah sakit sebagaimana yang di harapakan. Sedangkan tertib administrasi merupakan salah satu faktor yang menentukan di dalam upaya pelayanan kesehatan di rumah sakit.

\section{Keamanan dan Kerahasiaan}

\section{Keamanan}

a. Faktor intrinsik

Penyebab kerusakan yang berasal yang berasal dari benda arsip itu sendiri, misalnya kualitas kertas, pengaruh tinta, pengaruh lem pelekat dan lain-lain. Kertas dibuat dari campuran kimiawi, kertas akan mengalami perubahan dan rusak. Proses kerusakan itu bisa terjadi dalam waktu yang singkat, bisa pula memakan waktu bertahun-tahun. Demikian pula tinta dan bahan pelekat dapat menyebabakan proses kimia yang merusak kertas. b. Faktor ektrinsik

Penyebab kerusakan yang berasal dari luar benda arsip, yakni lingkungan fisik, organisme perusak, dan kelalaian manusia :

1) Faktor lingkungan fisik yang berpengaruh besar pada kondisi arsip antara lain temperatur, kelembaban udara, sinar matahari, polusi udara, dan debu.

2) Biologis, organisme perusak yang kerap merusak arsip antara lain jamur, kutu buku, rayap, kecoa, dan tikus.

3) Kimiawi, yaitu kerusakan arsip yang lebih diakibatkan merosotnya kualitas kandungan bahan kimia dalam bahan arsip.

4) Kelalaian manusia yang sering terjadi yang dapat menyebabkan arsip bisa rusak adalah percikan bara rokok, tumpahan atau percikan minuman, dan sebagainya.

\section{Kerahasiaan}

Informasi tentang pasien adalah rahasia dan rumah sakit diminta menjaga kerahasiaan informasi pasien serta menghormati kebutuhan privasinya. Rahasia adalah suatu yang disembunyikan dan hanya diketahui oleh satu orang, oleh beberapa orang saja, atau kalangan tertentu. Kerahasiaan merupakan pembatasan pengungkapan informasi pribadi tertentu. Dalam hal ini mencangkup tanggung jawab untuk menggunakan, mengungkapan, atau mengeluarkan informasi hanya dengan sepengetahuan dan izin individu.

\section{Ruang Penyimpanan Rekam Medis}

Ruang penyimpanan arsip (rekam medis ) harus dibangun dan diatur sebaik mungkin sehingga mendukung keawetan arsip.

1. Lokasi ruangan/gedung arsip sebaiknya terletak di luar daerah industri dengan 
luas yang cukup untuk menyimpan arsip yang sudah diperkirakan sebelumnya. Kalau merupakan bagian dari satu bangunan gedung, hendaknya ruang arsip terpisah dari keramaian kegiatan kantor lainnya dan tidak dilalui oleh saluran air.

2. Kontruksi bangunan sebaiknya tidak menggunakan kayu yang langsung menyentuh tanah untuk menghindari serangan rayap.

3. Ruangan sebaiknya dilengkapi dengan penerangan, pengatur temperatur ruangan, dan air conditioner (AC) yang bermanfaat untuk mengendalikan kelembaban udara didalam ruangan. Kelembaban udara di dalam ruangan. Kelembaban udara yang baik sekitar 50$60 \%$ dan temperatur sekitar $600-750 \mathrm{~F}$ atau $22^{\circ} \mathrm{C}-25^{\circ} \mathrm{C}$.

4. Ruangan harus selalu bersih dari debu, kertas berkas, putung rokok, maupun sisa makanan.

5. Alat penyimpanan seperti lemari, filling cabinet, rak, dan lainya sebaiknya terbuat dari logam tahan karat. Adapun alat pemeliharaanya antara lain mesin penghisap debu (vacum cleaner), termohigrometer (alat pengukur suhu dan kelembaban udara), alat pendeteksi api/asap (fire/ smoke derector), APAR dan lainnya.

\section{Metode Penelitian}

\section{Ruang Lingkup Penelitian}

Penelitian ini hanya dilakukan di ruang penyimpanan rekam medis RS Setia Mitra. mengenai Keamanan dan Kerahasiaan Ruang Penyimpanan Rekam Medis.

Metode penelitian yang digunakan adalah penelitian deskriptif yaitu suatu metode penelitian yang dilakukan dengan tujuan membuat gambaran atau deskriptif tentang suatu keadaan secara objektif, kemudian menganalisa masalah tersebut sesuai dengan hasil yang diamati.

Teknik pengumpulan data

1. Teknik Observasi
Melakukan observasi langsung pada objek penelitian dengan menggunakan instrument pengumpulan data untuk memperoleh data yang berhubungan dengan masalah yang diteliti.

\section{Wawancara}

Melakukan tanya jawab langsung kepada narasumber mengenai aspek keamanan dan kerahasiaan rekam medis di ruang penyimpanan.

\section{Teknis Analisa Data dan Pengolahan Data}

1. Pengolahan data

a. Pemeriksaan data

1) Memeriksa kelengkapan dan validasi data

2) Data disajikan dalam bentuk tabel

2. Teknik analisa data

a. Analisis data dengan cara membandingkan keamanan dan kerahasiaan rekam medis dengan teori.

b. Evaluasi data dan untuk melihat keamanan dan kerahasiaan di ruang penyimpanan sesuai tidak dengan standar.

c. Hasil penelitian dinyatakan dengan bentuk narasi.

\section{Hasil Penelitian}

Kebijakan Keamanan dan Kerahasiaan Ruang Penyimpanan Rekam Medis

a. Kebijakan Keamanan dan Kerahasiaan Rekam Medis

Berdasarkan hasil wawancara yang dilakukan penulis bahwa Kebijakan Keamanan dan Kerahasiaan Rekam Medis sudah dibuat dalama bentuk buku pedoman. Semua hal yang berkaitan dengan aspek keamanan dan kerahasiaan rekam medis sudah tercantum dalam kebijakan penyelenggaraan rekam medis. Kebijakan pengelolaan rekam medis, pelepasan informasi medis, dan hak 
akses data rekam medis sudah tertuang dalam kebijakan tersebut.

b. Standar Prosedur Operasional Keamanan dan Kerahasiaan Rekam Medis

Bedasarkan hasil wawancara yang dilakukan penulis ditemukan bahwa standar prosedur operasional yang terkait keamanan dan kerahasiaan rekam medis belum dibuat. Penulis hanya mendapatkan standar prosedur operasional pemeliharaan rekam medis.

\section{Pelaksanaan Keamanan dan Kerahasiaan} Rekam Medis

a. Keamanan

1) Faktor instrinsik

Berdasarkan hasil Penelitian yang di lakukan oleh penulis keamanan rekam medis dalam faktor instrinsik bahan kertas dan tinta yang di gunakan formulir sudah baik. Namun untuk kualitas map rekam medis belum menggunakan map yang berkualitas baik dan perekat map mudah terlepas.

2) Faktor Ekstrinsik

Berdasarkan hasil penelitian yang dilakukan oleh penulis keamanan rekam medis dalam faktor ekstrinsik, lingkungan sudah baik temperatur dan kelembaban normal namun masih terdapat debu dalam ruang penyimpanan. Ruang penyimpanan baik, tidak ada rayap, kutu, kecoa dan tikus. Sudah menggunakan kertas berkualitas baik. Petugas rekam medis setiap hari membawa makanan dan minuman ke dalam ruang penyimpanan.

b. Ruang Penyimpanan Rekam Medis

Berdasarkan hasil penelitian yang dilakukan oleh penulis, lokasi ruang penyimpanan rekam medis terletak dekat dengan dapur sehingga petugas lain dapat berlalu-lalang di ruang penyimpanan. Kontruksi bangunan sudah baik menggunakan beton, penerangan di ruang penyimpanan rekam medis sudah baik, ruang penyimpanan sudah menggunakan AC dan kelembaban sudah baik, ruangan di ruang penyimpanan tidak bersih masih banyak terdapat debu, kertas bekas dan sisa makanan. Ruang penyimpanan belum terdapat alat pemeliharaan seperti mesin penghisap debu, termohigrometer dan alat pendeteksi api/asap namun sudah terdapat APAR tetapi APAR hanya diletakan dilantai ruang penyimpanan rekam medis tanpa keamanan yang memadai.

Tabel 1. Hasil pengamatan petugas yang tidak memiliki hak akses masuk keruang penyimpanan rekam medis

\begin{tabular}{ccl}
\hline Hari & Jumlah & Kondisi Pintu \\
\hline 1 & 4 & Tidak Terkunci \\
2 & 6 & Tidak Terkunci \\
3 & 4 & Tidak Terkunci \\
4 & 3 & Tidak Terkunci \\
5 & 5 & Tidak Terkunci \\
\hline
\end{tabular}

c. Kerahasiaan Rekam Medis

Berdasarkan hasil penelitian di lakukan oleh penulis untuk kerahasiaan ruang penyimpanan rekam medis di rumah sakit belum terjaga kerahasiaannya dengan baik karena masih terdapat rekam medis yang rusak, terlipat dan terdapat formulir yang lepas dari map rekam medis, hal ini disebabkan rak penyimpanan tidak dapat menampung rekam medis, sehingga rekam medis ditumpuk di dalam rak penyimpanan.

\section{Pembahasan}

Kebijakan Keamanan dan Kerahasiaan Rekam Medis 
a. Kebijakan Keamanan dan Kerahasiaan Ruang Penyimpanan Rekam Medis

Berdasarkan hasil wawancara ditemukan bahwa Rumah Sakit Setia Mitra sudah memiliki Kebijakan terkait keamanan dan kerahasiaan ruang penyimpanan rekam medis . yaitu kebijakan yang bagaimana mengatur pengelolaan rekam medis, kebijakan pelepasan informasi medis, serta kebijakan petugas kesehatan yang memiliki akses data rekam medis yang berbentuk surat keputusan pedoman. Bedasarkan hasil penelitian terhadap kebijakan dan keamanan di ruang penyimpanan rekam medis, petugas rekam medis masih belum melaksanakan sesuai dengan kebijkaan yang sudah dibuat. Sebaiknya petugas rekam medis melakukan tugasnya sesuai dengan kebijakan yang sudah dibuat.

b. Standar Prosedur Operasional keamanan dan Kerahasiaan di ruang penyimpanan Rekam Medis

Standar prosedur operasional keamanan dan kerahasiaan rekam medis di RS Setia Mitra belum dibuat. Berdasarkan hasil wawancara dan penelusuran standar prosedur operasional yang penulis lakukan hanya standar operasioanal pemeliharaan rekam medis. Seharusnya ada prosedur yang berkaitan dengan keamanan di ruang penyimpanan rekam medis di dalam SPO tersebut. Pentingnya standar prosedur operasional keamanan ruang penyimpanan untuk menghindari hilangnya rekam medis dan hak akses ruang penyimpanan rekam medis.

\section{Pelaksanaan Keamanan dan Kerahasiaan Rekam Medis}

a. Keamanan Rekam Medis

1) Faktor intrinsik
Dari hasil penelitian di Rumah Sakit Setia Mitra, ditemukan bahwa kualitas kertas dan tinta yang digunakan untuk rekam medis sudah baik. Namun untuk bahan perekat dan map yang digunakan untuk melindungi rekam medis masih menggunakan bahan yang kualitasnya tidak baik. Map ada yang robek dan formulir mudah lepas dari map.

Berdasarkan teori Agus Sugiarto 2014, faktor intrinsik penyebab kerusakan arsip berasal dari benda arsip itu sendiri, misalnya kualitas kertas, pengaruh tinta, pengaruh lem perekat dan lain lain. Kertas dibuat dari campuran bahan yang mengandung unsur-unsur kimia. Karena proses kimiawi, kertas akan mengalami perubahan dan rusak. Proses kerusakan itu bisa terjadi dalam waktu yang singkat, bisa pula memakan waktu bertahun-tahun. Demikian pula tinta dan bahan perekat dapat menyebabkan proses kimia yang merusak kertas.

\section{2) Faktor ekstrinsik}

Berdasarkan hasil penelitian yang di lakukan oleh penulis ruang penyimpanan rekam medis di rumah sakit masih terdapat debu di dalam ruang penyimpanan dan petugas rekam medis setiap hari membawa makanan dan minuman ke dalam ruang penyimpanan.

Berdasarkan teori Agus Sugiarto 2014, faktor ekstrinsik penyebab kerusakan arsip berasal dari luar benda arsip, yakni :

a) Faktor lingkungan fisik yang berpengaruh besar pada kondisi arsip antara lain temperatur, kelembaban udara, sinar matahari, polusi udara, dan debu.

b) Biologis, organisme perusak yang kerap merusak arsip antara lain jamur, kutu buku, rayap, kecoa, dan tikus. 
c) Kimiawi, yaitu kerusakan arsip yang lebih diakibatkan merosotnya kualitas kandungan bahan kimia dalam bahan arsip.

d) Kelalaian manusia yang sering terjadi yang dapat menyebabkan arsip bisa rusak adalah percikan bara rokok, tumpahan atau percikan minuman, dan sebagainya.

b. Ruang Penyimpanan Rekam Medis

1) Ruang penyimpanan

Berdasarkan hasil penelitian yang dilakukan oleh penulis, pintu ruang penyimpanan tidak di kunci dan petugas selain rekam medis dapat masuk ke ruang penyimpanan. Saat penelitian dilakukan, penulis melihat ada 10 perawat, 3 fisioterapi, 2 IT, 2 radiologi, 4 logistik, dan 1 gizi masuk kedalam ruang penyimpanan rekam medis.

Berdasarkan teori Standar Nasional Akreditas Rumah Sakit tahun 2018 tentang standar Manajemen Informasi dan Rekam Medis 11 "berkas rekam medis dilindungi dari kehilangan, kerusakan, gangguan serta akses dan penggunaan yang tidak berhak" dengan elemen penilaian MIRM (Manajemen Informasi dan Rekam Medis) 11, pertama terdapat regulasi ditetapkan untuk mencegah akses penggunaan rekam medis bentuk kertas dan atau elektronik tanpa izin. Kedua rekam medis dalam bentuk kertas dan atau elektronik dilindungi dari kehilangan dan kerusakan. Ketiga rekam medis dalam bentuk kertas dan atau elektronik dilindungi dari gangguan dan akses serta penggunaan yang tidak sah. Keempat ruang dan tempat penyimpanan rekam medis menjamin perlindungan terhadap akses dari yang tidak berhak.

\section{2) Lokasi Ruang Penyimpanan}

Berdasarkan hasil penelitian yang dilakukan oleh penulis, ruang penyimpanan rekam medis berada dekat dengan dapur sehingga petugas lain dapat berlalu-lalang di ruang penyimpanan. Kontruksi bangunan sudah baik menggunakan beton, penerangan di ruang penyimpanan rekam medis sudah baik, temperatur ruang penyimpanan dan kelembaban sudah baik, ruangan di ruang penyimpanan tidak bersih masih banyak terdapat debu, kertas bekas dan sisa makanan. Ruang penyimpanan belum terdapat alat pemeliharaan seperti mesin penghisap debu, termohigrometer dan alat pendeteksi api/asap namun sudah terdapat APAR tetapi APAR hanya diletakan dilantai ruang penyimpanan rekam medis tanpa keamanan yang memadai.

Bedasarkan teori Agus Sugiarto 2014, ruang penyimpanan arsip (rekam medis ) harus dibangun dan diatur sebaik mungkin sehingga mendukung keawetan arsip :

a) Lokasi ruangan/gedung arsip terletak di luar daerah industri dengan luas yang cukup untuk menyimpan arsip yang sudah diperkirakan sebelumnya. Kalau merupakan bagian dari satu bangunan gedung, hendaknya ruang arsip terpisah dari keramaian kegiatan kantor lainnya dan tidak dilalui oleh saluran air.

b) Kontruksi bangunan tidak menggunakan kayu yang langsung menyentuh tanah untuk menghindari serangan rayap.

c) Ruangan dilengkapi dengan penerangan, pengatur temperatur ruangan, dan air conditioner (AC) yang bermanfaat untuk mengendalikan kelembaban udara didalam ruangan. Kelembaban udara di dalam ruangan. Kelembaban udara yang baik 
sekitar $50-60 \%$ dan temperatur sekitar $600-750 \mathrm{~F}$ atau $22^{\circ} \mathrm{C}-25^{\circ} \mathrm{C}$.

d) Ruangan selalu bersih dari debu, kertas berkas, putung rokok, maupun sisa makanan.

\section{c. Kerahasiaan Rekam Medis}

Berdasarkan hasil penelitian di lakukan oleh penulis untuk kerahasiaan ruang penyimpanan rekam medis di rumah sakit belum terjaga kerahasiaannya dengan baik karena masih terdapat rekam medis yang rusak, terlipat dan terdapat formulir yang lepas dari map rekam medis, dan dibiarkan begitu saja tanpa ada perawatan pada rekam medis yang rusak. Hal ini disebabkan rak penyimpanan tidak dapat menampung rekam medis, sehingga rekam medis di tumpuk di dalam rak penyimpanan.

Berdasarkan Permenkes RI No.36 tahun 2012 pasal 5 ayat 1 "Rahasia kedokteran dapat dibuka hanya untuk kepentingan kesehatan pasien, memenuhi permintaan aparatur penegak hukum dalam Informasi yang bersifat rahasia dapat berupa tulisan maupun verbal rangka penegak hukum dalam rangka penegakan hukum, permintaan pasien sendiri, atau bedasarkan ketentuan peraturan perundangundangan. Menurut Peraturan Menteri Kesehatan Republik Indonesia No.269 / Menkes / Per / III /2008 Bab V pasal 14 tentang tanggung jawab Rekam Medis menyebutkan bahwa "pimpinan sarana kesehatan bertanggung jawab atas hilang, rusak, pemalsuan, dan/atau penggunaan oleh orang atau badan yang tidak berhak terhadap rekam medis.

\section{Kesimpulan}

Berdasarkan hasil penelitian dan pembahasan di atas, penulis menyimpulkan:
1. Kebijakan keamanan dan kerahasiaan ruang penyimpanan rekam medis di Rumah Sakit Setia Mitra sudah dibuat, namun belum dilaksanakan sepenuhnya. Standar Prosedur Operasional terkait keamanan dan kerahasiaan ruang penyimpanan rekam medis belum dibuat.

2. Ruang penyimpanan rekam medis belum menjamin keamanan dan kerahasiaan rekam medis hal ini disebabkan pintu ruang penyimpanan tidak dikunci sehingga petugas yang tidak memiliki akses dapat masuk keruang penyimpanan. Ruang penyimpanan belum terdapat alat pemeliharaan seperti mesin penghisap debu, termohigrometer dan pendeteksi api/asap. Kerahasiaan rekam medis di ruang penyimpanan belum terjaga dengan baik dikarenakan belum sesuai dengan Permenkes RI No. 269 tahun 2008 seperti masih terdapat rekam medis yang rusak dan menyelip.

\section{Saran}

1. Sebaiknya perlu menegaskan dan mensosialisasikan kembali ketentuan yang sudah ditetapkan dalam kebijakan yang berlaku dalam kebijakan keamanan dan kerahasiaan di ruang penyimpanan rekam medis. Sebaiknya dibuat standar prosedur operasional tentang menjaga kerahasiaan dan kemanan ruang penyimpanan rekam medis, agar keamanan dan kerahasiaan rekam medis dapat terjaga.

2. Sebaiknya untuk keamanan ruang penyimpanan rekam medis di batasi oleh hak akses seperti fingerprint. Ruang penyimpanan hendaknya dilengkapi alat pemeliharan seperti vacuum cleaner, termohigrometer dan pendeteksi api/asap. Untuk menjamin kerahasiaan sebaiknya rekam medis yang rusak dilakukan penggantian rekam medis yang baru agar kualitas rekam medis tetap terjaga. 


\section{Daftar Pustaka}

Anwar, Desy., Kamus Besar Bahasa Indonesia, (Surabaya: 2015)

Direktorat Jenderal Pelayanan Medik, Pedoman Penyelenggaraan dan Prosedur Rekam Medis Rumah Sakit di Indonesia, (Jakarta: Departemen Kesehatan Republik Indonesia, 2006).

Departemen Kesehatan Republik Indonesia, Pedoman Penyelenggaraan dan Prosedur Rekam Medis (Jakarta : Depkes RI, 1997)

Edna K.Huffman,RRA. Health Information Management, Edisi10.(Berwyn lionis : Physilians'Record company :1994)

Hatta, Gemala R. Pedoman Manajemen Informasi Kesehatan di Sarana Pelayanan Kesehatan, (Jakarta : UIPRES, 2009)

Komisi Akreditas Rumah Sakit (KARS), Standar Nasional Akreditas Rumah Sakit Edisi 1 Tentang Akses ke Rumah Sakit dan Kontinuitas Pelayanan, (Jakarta : 2018)

Martono, Boedi., Manajemen Unit Kerja Rekam Medis, (Yogyakarta: Pustaka Pinar Harapan, 1997)

M. Budiahardjo., Panduan menyusun standar Operating Procedure, (Jakarta: RAS, 2014)

Notoatmojo, Soekidjo, Metode Penelitian kesehatan, (Jakarta : Rineka Cipta, 2013)

Peraturan Menteri Republik Indonesia 269/Menkes/Per/III/2008 tentang Rekam Medis.

Peraturan Menteri Republik Indonesia No 55 Tahun 2013. Penyelenggaraan Pekerjaan Perekam Medis

Purnamasari, Evita P., panduan menyusun Standar Operating Procedure, (Jogjakarta: Kobis, 2015)

Rustiyanto, Ery., Etika Profesi Perekam Medis Informasi Kesehatan, (Jogjakarta : 2009)

Sailendra, Annie., Langkah-langkah praktis membuat SOP, (Jogjakarta : Trans : RAS, 2014)
Sugiarto, Agus., Manajemen Kearsipan Modern, (Yogyakarta : penerbit gava media, 2005) 